

\title{
1999 YEAR REPORT
}

Address:
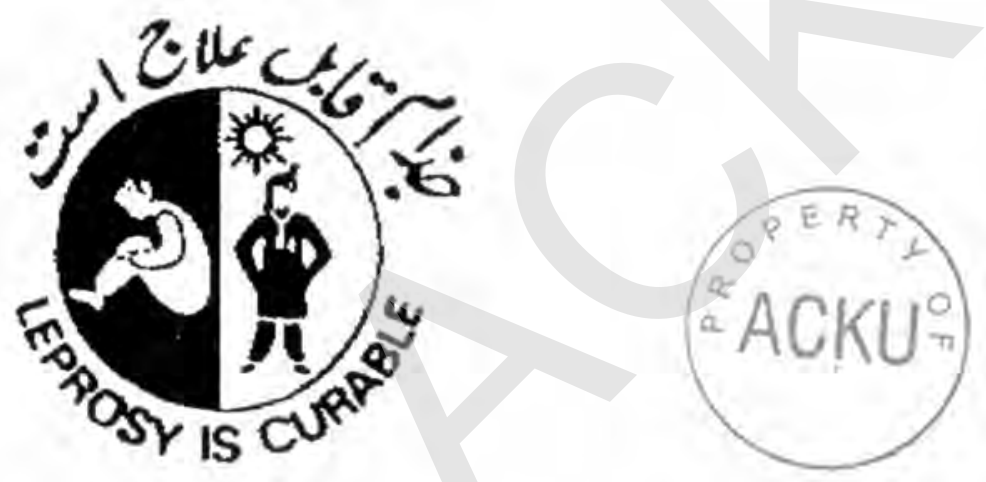

Afghanistan

: St. no. 3, Nowshad Project

Dasht-i-Shor

Mazar-i-Sharif

Pakistan : House nr. 2 Afzalabad, Old Barra road

University town, Peshawar

tel/ fax: 009291845393

e-mail : malc@lepco.pwr.sdnpk.undp.org

Postal address : P.O. Box 819, University Town, Peshawar, Pakistan 
Table of Contents:

\section{Page}

- Introduction

3

- History of LEPCO

3

- General developments

- Analysis of activities, targets and objectives versus achieved results

- Epidemiological developments Leprosy

Tuberculosis

General

- Financial aspects

- Conclusion

- Maps: Afghanistan

Central Afghanistan

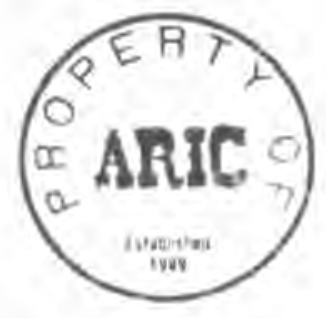




\section{Introduction}

A report is presented on the activities and achievements of LEPCO during 1999. In this report an analysis is made to which extent the targets set in the 1999 plan of action have been achieved.

\section{History of LEPCO:}

During the last years of the 1970's and the 80's, large numbers of Afghan refugees arrived in Pakistan because of the war in Afghanistan. Among these refugees, there were many leprosy patients, the fast majority from one ethnic group, the Hazaras. The Hazara's are from Hazarajat, an isolated and mountainous area in central Afghanistan.

Because of the high number of leprosy patients among the Hazara's, Dr. Ruth Pfau, at that time in charge of the Pakistan leprosy control program, went into Afghanistan with two Afghans who had been trained as leprosy technicians in Pakistan. Not only did they find many leprosy patients, they also found out that in large parts of Hazarajat, general health care was virtually non existent.

A clinic was therefore opened in Malestan and later another one in Sheikh Ali. Gradually the program was expanded. At present there are nine LEPCO clinics in Hazarajat. Leprosy control remained first priority for the LEPCO clinics, but in the absence of general healthcare facilities they have had to treat lots of general patients as well. In 1994. a TB control component was added to the program. In recent years there has been a major reduction in the leprosy case load and more general health facilities have become available in Hazarajat. As much as possible LEPCO now tries to hand over general healthcare tasks to other organizations and focuses on TB and leprosy control only. TB control has now become the mainstay of activities in the LEPCO clinics.

In the meantime LEPCO had shifted its main office from Quetta in Pakistan to Mazar-iSharif in northern Afghanistan. In Mazar-i-Sharif a new clinic was opened, this clinic was involved only in TB and leprosy control. The TB control program of this clinic covered only a small area of the town, plans for expansion of the program to cover the whole town had been made in early 1997. During that year however the security situation in Mazar-ISharif seriously deteriorated, forcing most foreigners to leave the city. The plans for expansion of the TB control program had to be postponed several times. This situation of insecurity and lawlessness continued during 1998. LEPCO therefore established a suboffice in Peshawar, Pakistan, in October 1997. 


\section{General developments:}

1999 has been a good year for LEPCO. There was relatively little fighting and travelling inside Afghanistan was relatively easy and safe, Most of the planned activities could be carried out and a lot of progress was made towards improving the TB control program.

The war in Afghanistan has been dragging on for over twenty years now. In the first 10 years, a loose coalition of mujahedeen parties were fighting the government forces backed by Russian troops. The Russians withdrew in 1989, two and a half years later, in April 1992, the mujahedeen succeeded in defeating the government forces and taking the capital Kabul. Even at the time of the Russian occupation, the mujahedeen had also been fighting eachother. This internal fighting further escalated when they took Kabul. Fighting between mujahedeen groups went on in many different parts of the country, Kabul was largely destroyed as a result of this.

In 1994 a new force appeared on the scene, the Taliban. The Taliban, a faction of very strict Sunni Muslims, wanted to bring back law and order to Afghanistan and impose their rather strict interpretation of Islam on all Afghans. The Taliban are mainly Pashtuns. the largest ethnic group of Afghanistan. Especially their rules about total separation of the sexes, make it very difficult for aid agencies to provide aid to women and children. Over the years the Taliban gradually extended their territory. At present they control about $90 \%$ of the country. All but one of the LEPCO clinics are now in areas under control of the Taliban.

After a year full of violence, culminating in the massacre among Hazara civilians in August 1998, Mazar-I-Sharif became quiet again during the first half of 1999. In the northern part of Hazarajat, fighting continued throughout the winter until May '99. In May Bamian, the capital of Hazarajat, changed hands twice. After Bamian was recaptured by the Taliban towards the end of that month, opposition forces fled the area. Since then there has been little fighting. At present most of Hazarajat is under control of a Hazara faction loyal to the Taliban, only Lal sar Jangal is still under control of the opposition. It is however widely believed that during the winter months, when Taliban supply lines will be cut off by the snow, fighting will resume.

With the exception of the northern part of Hazarajat, access to the LEPCO project areas has not been restricted by security problems throughout the year. By the time the snow had melted and the water in the rivers had come down to such level that the roads were open again, security wise the northern part of Hazarajat had also become accessible again The clinics in Behsud, Yakaolang and Bamian had been closed since September 1998 when they were looted. The Bamian and Yakaolang clinics have not yet been re-opened for fears of renewed fighting this winter. The Behsud clinic was re-opened in a new location in December '99. In Mazar-I-Sharif a TB control program covering the whole town was started in July. 
All clinics that were open were visited at least three times during the year for supervision by one of the two ex-patriate medical officers. A one year drug supply reached all clinics in Hazarajat towards the end of November. Throughout the year there has been no shortage of TB and/or leprosy drugs and/ or reagents meeded for AFB microscopy in any of the clinics. Sufficient budget until the end of May 2000 has been provided to all clinics in Hazarajat. Drugs and budget for the clinic in Mazar are being provided on a continuous basis.

Some major steps were taken during 1999 towards integration of the LEPCO TB control program into existing general health facilities. The clinic in Saydabad, that had become too small, was closed and moved to nearby Chak. In Chak a new building was constructed on the grounds of a busy general hospital run by a small German NGO. The LEPCO clinic now serves as a TB and leprosy control unit only and gets suspect cases referred by the hospital OPD. In Behsud a similar approached has been followed. The clinic that was looted in September 1998 was not re-opened. In stead a new building was constructed on the grounds of the district hospital of Behsud in Gardan Dewal. On this location Médecins sans Frontières (MSF) run a general clinic. LEPCO again acts as a TB and leprosy control unit only, getting referrals from the MSF clinic. In Panjao a new clinic was opened in November, this clinic is also integrated into a district hospital, run by Action Contre la Faim (ACF), a French NGO. LEPCO again runs only a TB and leprosy control unit. In Mazar-I-Sharif a TB control program was started in July. The LEPCO clinic there only diagnoses and treats cases of TB and leprosy and gets referrals from the network of clinics in Mazar run by MSF. In all those clinics naturally there are also many self referrals.

In Malestan, Jaghori and Waras no suitable partner could be identified for such cooperation so far, it is hoped that we will succeed in doing so in the future. For now those clinics are still providing general health care as well. In Lal a small part of the general health care tasks could be handed over to the International Assistance Mission (IAM), an American NGO. The main advantage of this co-operation for LEPCO has been the presence throughout the year of at least one ex-patriate medical doctor of IAM, authorized to also supervise the medical activities of the LEPCO staff. This has already resulted in major improvements in the Lal clinic.

The Bamyan and Yakaolang clinics have not been re-opened yet. For Bamyan it is hoped that plans made during the previous winter for a common program in the Bamyan hospital will be revived. If there is no more fighting, LEPCO could re-start its activities in Bamyan as a TB and leprosy control unit, with other NGOs running the general health services next summer. In Yakaolang we also hope to be able to re-open next summer, depending on the security situation. Until now there is little prospect of being able to hand over general healthcare tasks to another NGO there.

As will be explained in more detail in the section on epidemiological developments, the leprosy caseload has been very much reduced. TB control has become the main activity now. In Hazarajat all smear positive TB patients are now kept on admission for the first two months, in Mazar-I-Sharif the patients may choose between being admitted or 
coming daily. So far this strategy seems to work fairly well, over the first 8 months of 1999 a conversion rate of $92 \%$ (excluding the dead) has been achieved. Though most of the year only five out of ten clinics were open, there was also a marked increase, in absolute numbers as well as in proportion to other cases, of smear positive cases being diagnosed. With records up to date until mid November for all clinics, 201 smear positive cases ( new cases, relapses and others) have been detected during 1999, as compared to 126 smear positive cases during the whole of 1998. Smear positives now make up $49 \%$ of the case detection, as compared to $36 \%$ during 1998. The cure rate for new smear positives dropped during 1998 as a result of the disturbances in Mazar-I-Sharif, but recovered already up to its old level of $85 \%$ for patients registered during the second half of that year. All this is explained in more detail in the section on epidemiological developments.

There have also been major improvements in the laboratories of the LEPCO clinics. Partly this is due to the appointment of a laboratory supervisor in June '99, partly this is due to a consequent system of quality control in which all positive slides and $10 \%$ of negative slides are cross checked by a referral laboratory in Peshawar. Quality control results were excellent, only in Mazar there was a problem of false negatives during the first 3 months of the program there. The lab technician who was newly appointed in July has since improved his performance and for the months of Oetober and November there were no more false negatives, nor false positives.

After two difficult years, LEPCO now seems well on its way towards achieving its main objective of establishing itself as a serious TB control program. Detection of smear positive cases is on the increase; unless affected by security problems, cure rates remain above $80 \%$. At the same time there is continued attention for the leprosy control component and efforts continue to be made to improve management in the clinics of the remaining cases of leprosy.

In addition to its tasks of supporting the LEPCO program in Afghanistan, the LEPCO office in Peshawar has supported a program for aid to disabled children in North West Frontier Province (NWFP) in Pakistan. For these children, mostly children of Afghan refugees, funds have been made available for surgical intervention by 'Stichting Liliane Fonds" (SLF) from the Netherlands. The operations are performed by a local orthopaedic surgeon. The funds are channeled through LEPCO by SLF. This is a completely separate program, with its own accounts and records. Financial record keeping and basic monitoring is done by the LEPCO office. Altogether 170 children were operated during 1999 , an amount equivalent to US\$21,808 was spent for this purpose. This amount is not part of the expenditures of LEPCO mentioned on page 25 and 26 and was entirely provided by SLF. 
Analysis of activities, targets and objectives versus achieved results:

3. Activities planned according to the priorities to reach the objectives:

Number

3.1

3.1 .1

3.1 .2

To have 7 laboratory staffs

(re)trained in AFB microscopy.

\section{Result}

Achieved

To conduct a one week refresher

course on TB and leprosy for two

groups of 10 consisting of LEPCO

staff and general health workers

Not achieved, on the job

training was provided though by the laboratory supervisor.

Excellent results of quality control made further training courses less relevant.

\section{1 .3}

To have the LEPCO medical officer trained in leprosy in ALERT.

3.1 .4

To have two candidates from Hazarajat

Achieved enrolled in the training course for Leprosy Technicians at Marie Adelaide Leprosy

Centre in Karachi

3.2.1 To maintain adequate healthcare services in nine LEPCO clinics

Achieved

Organisation

3.2 .2

To maintain a TB and leprosy control system in accordance with WHO and ILEP guidelines in 8 LEPCO clinics in Hazarajat and Saydabad.

3.2.3 To involve clinics of MSF, SCA, Shuhada and Ibn Sina in treatment Achieved in those clinics that were open

Achieved in those clinics that were open

of leprosy and TB in Hazarajat

Not achieved. Set up has been changed, TB patients are kept on admission for the duration of the intensive phase. 


\section{Result}

To maintain a TB and leprosy

Achieved

control system in the LEPCO

clinic in Mazar-i-Sharif according

to WHO/ ILEP guidelines.

3.2.5 To expand the TB control program

in Mazar-i-Sharif to cover the whole

city through involvement of Mulki

Hospital and MSF and HABITAT

clinics.

3.2.6 To select among field assistants, or newly employ seven additional laboratory technicians/ assistants

3.2.7 To select, train and employ new field assistants for those promoted to laboratory assistant/ technicians

3.2.8 To conduct supervisory visits to all 8 LEPCO clinics in Hazarajat and Saydabad at least twice yearly.

3.2.9 To conduct supervisory visits to the LEPCO clinic and to all other health facilities involved in the TB program in Mazar.

3.2.10 To order all general drugs, TB and leprosy drugs and reagents needed Achieved, though the set up had to be changed as Habitat clinics in Mazar are no longer functional and MSF have suspended their TB control program in Mazar.

Achieved Achieved for those clinics that were open in all LEPCO clinics and other clinics involved in the TB control program.

3.2.11 To supply the LEPCO clinics in Achieved Hazarajat and Saydabad with general Achieved for those clinics that were open drugs as well as tuberculosis and leprosy drugs.

Achieved

Achieved 
To maintain an uninterrupted

Achieved

supply of anti TB and anti leprosy

drugs in the LEPCO clinics and all

other clinics involved in the TB and

leprosy control program in Hazarajat.

3.2.13 To supply laboratory reagents

Achieved

to the laboratories involved in

the TB control program in

Hazarajat and Saydabad.

To maintain an uninterrupted supply of anti TB drugs

to the LEPCO clinic and all other

clinics involved in the TB control program in Mazar-i-Sharif.

To maintain an uninterrupted supply of laboratory reagents to all laboratories involyed in the TB control program in Mazar-i-Sharif.

3.2.16 To maintain an adequate reporting and recording

Achieved system in the LEPCO clinic and in all other clinics involved in the TB control program in Mazar-i-Sharif.

3.2.17 To maintain an adequate Achieved reporting and recording system in the LEPCO clinics and in all other clinics involved in the TB control program in Hazarajat and Saydabad.

3.2.18 To visit all elinics three times for administrative and supply Achieved purposes. 
Number

3.2 .19

3.2 .20

3.2 .22

3.2 .23

\section{Activity}

To maintain the LEPCO office

in Mazar-i-Sharif.

To maintain the LEPCO

office in Peshawar.

To maintain the LEPCO clinics

To have additional rooms for in-patients constructed in Yakaolang and Behsud clinics.

To maintain a quality control system for laboratories involved in the TB control program in Hazarajat and Saydabad.

To maintain a quality control system for laboratories involved in the TB control program in Mazar-i-Sharif.

To conduct meetings with all other organisations involved in healthcare delivery in Hazarajat.

To conduct regular meetings with all other organisations involved in the TB control program in Mazar-i-Sharif.

To prepare a leprosy section in the manual for the TB control program.

To print the revised TB and leprosy manual.

\section{Result}

Achieved

Achieved

Achieved for those clinics that were open

Achieved in Behsud, a complete new clinic was built here. Not achieved in Yakaolang, the clinic there has not been re-opened yet.

Achieved

Achieved

Achieved

Achieved

Achieved

Achieved 
Number

3.2 .29

3.2 .30

3.2 .31

3.3

3.3.I

3.3 .2

3.3 .3
Provision of TB control services from general health facilities In Mazar-I-Sharif.

\section{Result}

Not achieved

Achieved

Not achieved, several chapters were completed though. Completing the handbook is part of the, activities planned for the year 2000.

Delivery of Services

Running of 9 LEPCO clinics

Achieved for those clinics that were open

Not achieved, the set up of the program has changed. Most of the general clinics intended to be used in this program have been closed.

Provision of TB and leprosy control Not achieved, three of the services from general health facilitiesLEPCO clinics in Hazarajat in Hazarajat. have however been integrated into general health facilities.

\subsection{Community Education and Participation}

3.4.1 To health educate all patients

Achieved attending LEPCO clinics on general hygiene and healthcare as well as on tuberculosis and leprosy

3.5 Monitoring and evaluation

3.5.1 Drafting 1998 annual progress report Achieved 

reports on TB and leprosy in Mazar-i-Sharif general healtheare in Hazarajat and Saydabad.

3.5.3 To maintain a database on all TB

Achieved cases registered in the TB control programmes in Mazar and Hazarajat (+ Saydabad).

3.5.4 Drafting annual workplan and Achieved budget for 2000 for the period of July ' 98 till June ' 99 and presenting it to the auditor. statistics 


\section{Epidemiological developments:}

Due to the inaccessibility of Hazarajat during the winter months, it will not be possible to report on the final months of 1999 until next spring. Therefore in this year report we will report on 1998 and 1999 until 15 November. Also data have now become available on leprosy cases registered during previous years as all patients registered since the beginning of the program in 1984 have now been entered in a database.

\section{Leprosy:}

As shown in table I, since the beginning of the program in 1984 until mid November 1999, altogether 804 leprosy patients have been registered. Out of those 481 were 'New cases', 258 were 'Treatments after default', 4 were 'Relapses', 16 were 'Re-admissions' and 45 were 'Transfers' in. Most of the 'Treatments after default' had previously been treated by Marie Adelaide Leprosy Centre (MALC) in Karachi or German Medical Services (GMS) in Kabul. Some among them may have been 'Transfers in' rather than 'Treatments after default'.

It is very hard to draw any meaningful conclusion from the available data. Chart 1 shows the annual case detection and registered prevalence over the years. There have obviously been major fluctuations in annual case detection, partly this can be explained by the opening of new clinics. The peak in 1987 is due entirely to the opening of a new clinic in Lal sar Jangal.

The grade 2 disability rate among new patients varies from $8 \%$ so far for 1999 to $100 \%$ in 1986 (only 2 new patients were registered that year). The overall grade 2 disability rate is $37 \%$. The high overall grade 2 disability rate could be due to patients reporting late, it could however also be due to old patients being wrongly classified as new cases. As can be seen in Chart 2, there appears to be a gradual downward trend.

The child proportion has varied from $0 \%$ in 1985 and 1986 (only 7 new patients were registered in this period) to $37 \%$ in 1991 . The overall child proportion is $12 \%$, there is no obvious trend (see Chart 2).

Data on registered prevalence of leprosy are available only from 1995 onwards. As can be seen in Chart 1 , they show a consistent downward trend since that time. To a large extent this is due to starting on MDT most patients who were previously on monotherapy, thereby reducing the duration of their treatment; and to reducing the duration of $\mathrm{MB}$ MDT treatment from 2 years to 1 year. However annual case detection since 1995 shows a similar downward trend. Five years is still a short period though and there have been too many other factors involved (such as closure of clinics due to war) to reliably confirm such a trend.

By mid November 1999, only 44 patients were left on treatment. Out of those 33 were on MB, 3 on PB and 8 were on monotherapy. The 8 patients still on monotherapy have not been seen throughout the year and have most probably defaulted. They all live very far 
from any of the clinics and were given a one year supply of Dapsone at the end of last year. If ever they show up again, they will be started on MDT

During 1998, 23 new cases were detected. Among those 4 (17\%) were below 15 years of age and $4(17 \%)$ had grade 2 disabilities at the start of treatment. Until mid November during 1999,14 new cases were detected, $4(29 \%)$ were below 15 years of age, $1(8 \%)$ had grade 2 disabilities.

The 1995-1996 MB cohort and the 1997-1998 PB cohort were analyzed. Treatment completion rates were $81 \%$ and $87 \%$ respectively (the dead excluded). Complete results are shown in Table 3. There appears to have been a slight increase in the defaulter rate compared to previous years, this might also be a reflection of more accurate records due to increased supervision.

\section{Table 1 Case detection leprosy 1984-1999}

Clinic :ALL

Year :1984-1999

Quarter: ALL

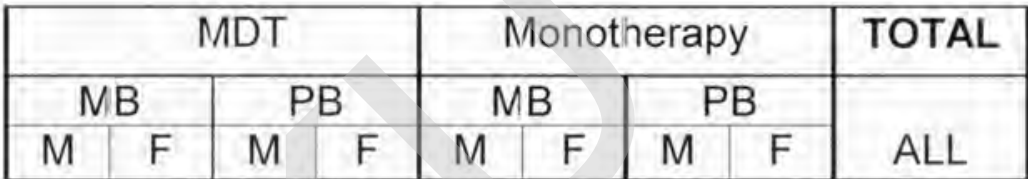

\begin{tabular}{|l|r|r|r|r|r|r|r|r|r|}
\hline 2 New patients never treated before & 153 & 107 & 59 & 29 & 73 & 38 & 13 & 9 & 481 \\
\hline 2.1 age 0-14 years & 15 & 14 & 12 & 9 & 4 & 4 & 1 & 1 & 58 \\
\hline 2.2 age 15+ & 138 & 93 & 47 & 20 & 69 & 34 & 12 & 8 & 423 \\
\hline 2.3 With disability grade 0 & 52 & 26 & 32 & 18 & 25 & 4 & 6 & 6 & 169 \\
\hline 2.4 With disability grade 1 & 52 & 32 & 10 & 4 & 16 & 8 & 1 & 2 & 125 \\
\hline 2.5 With disability grade 2 & 47 & 45 & 15 & 6 & 29 & 26 & 4 & 1 & 173 \\
\hline 2.6 With unknown disab.grade & 2 & 4 & 2 & 1 & 3 & 0 & 2 & 0 & 14 \\
\hline 3 Relapses after MDT & 2 & 2 & 0 & 0 & 0 & 0 & 0 & 0 & 4 \\
\hline 4 Transferred in & 27 & 6 & 5 & 0 & 4 & 2 & 1 & 0 & 45 \\
\hline 5 Re-admissions & 112 & 22 & 24 & 4 & 92 & 15 & 4 & 1 & 274 \\
\hline $6 \quad$ Total additions (2+3+4+5) & 294 & 137 & 88 & 33 & 169 & 55 & 18 & 10 & 804 \\
\hline
\end{tabular}


Table 2 : Case detection leprosy 1998

Clinic :ALL

Year :1998

Quarter: ALL

\begin{tabular}{|c|c|c|c|c|c|c|c|c|}
\hline \multicolumn{4}{|c|}{ MDT } & \multicolumn{4}{|c|}{ Monotherapy } & TOTAL \\
\hline & MB & & $\mathrm{PB}$ & & $\mathrm{MB}$ & & $\mathrm{PB}$ & \\
\hline$M$ & $\mathrm{~F}$ & $M$ & $\mathrm{~F}$ & $M$ & $\mathrm{~F}$ & $M$ & $\mathrm{~F}$ & ALL \\
\hline
\end{tabular}

PATIENTS ON TREATMENT AT THE BEGINNING OF THE PERIOD

\begin{tabular}{|l|r|r|r|r|r|r|r|r|r|}
\hline 1 Total & 97 & 52 & 6 & 4 & 44 & 11 & 3 & 1 & 218 \\
\hline
\end{tabular}

\section{PATIENTS REGISTERED DURING THE QUARTER OF REPORT}

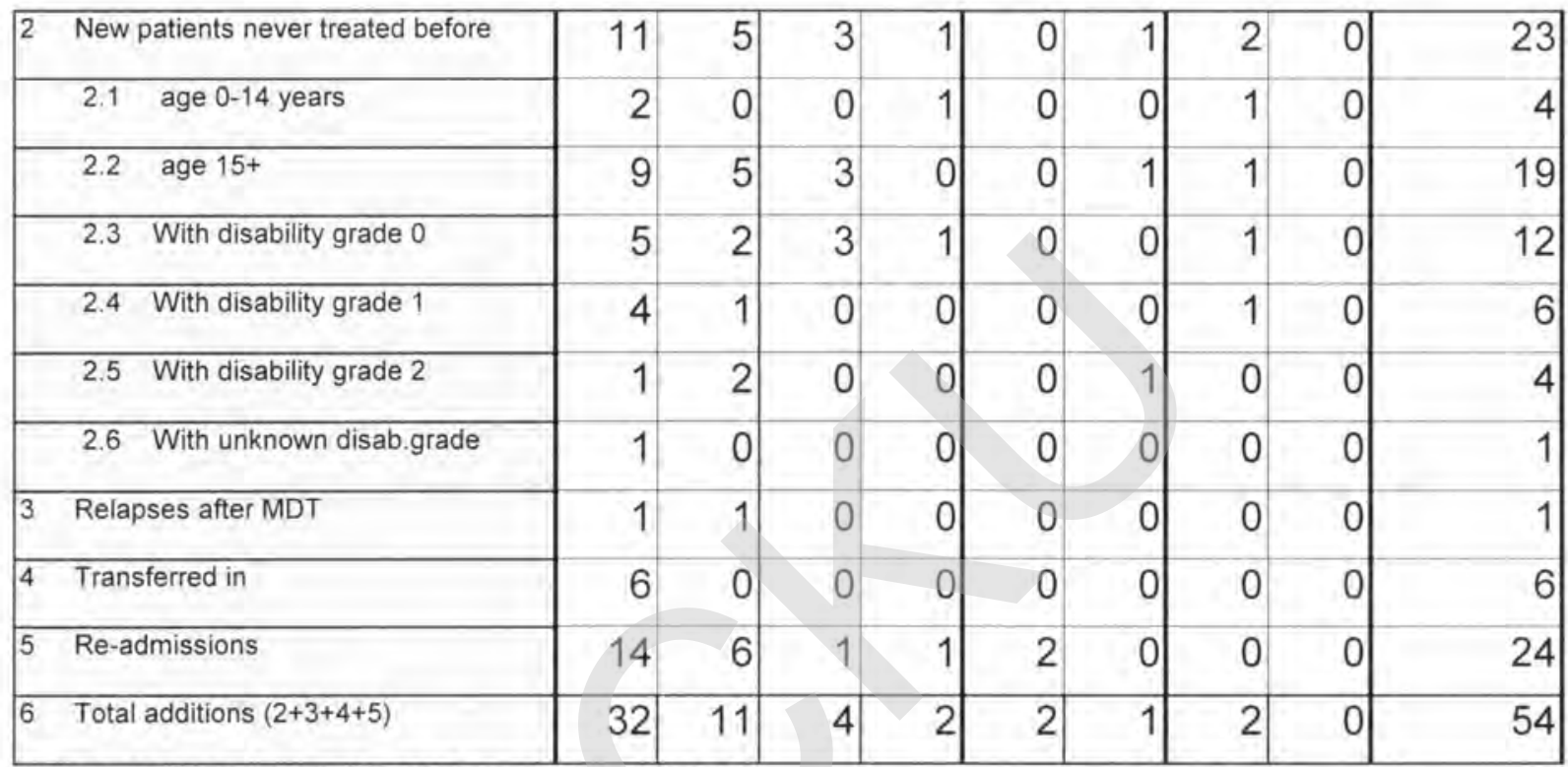

PATIENTS REMOVED FROM THE REGISTER

\begin{tabular}{|ll|r|r|r|r|r|r|r|r|r|}
\hline 7 & Treatm. completed as prescribed & 44 & 22 & 6 & 2 & 2 & 0 & 0 & 0 & 78 \\
\hline 8 Died & 0 & 1 & 0 & 0 & 1 & 0 & 0 & 0 & 2 \\
\hline 9 Transferred out & 3 & 2 & 0 & 0 & 16 & 6 & 1 & 1 & 29 \\
\hline 10 Out of control & 7 & 4 & 1 & 0 & 5 & 1 & 0 & 0 & 18 \\
\hline 11 Total deductions $(7+8+9+10)$ & 54 & 29 & 7 & 2 & 24 & 7 & 1 & 1 & 125 \\
\hline
\end{tabular}

PATIENTS ON TREATMENT AT THE END OF THE PERIOD

\begin{tabular}{|l|l|l|l|l|l|l|l|l|r|}
\hline 12 Total (1+6-11) & 75 & 34 & 3 & 4 & 22 & 5 & 4 & 0 & 147 \\
\hline 13 Patients registered for care only & & & & & & & & & \\
\hline
\end{tabular}


Table 3 : Case detection leprosy 1999 until mid November

Clinic :ALL

Year : 1999

Quarter: All until 15 November

\begin{tabular}{|c|c|c|c|c|c|c|c|c|}
\hline \multicolumn{4}{|c|}{ MDT } & \multicolumn{4}{|c|}{ Monotherapy } & TOTAL \\
\hline & $\mathrm{MB}$ & & PB & & $\mathrm{MB}$ & & $\mathrm{PB}$ & \\
\hline$M$ & $\mathrm{~F}$ & $M$ & $\mathrm{~F}$ & M & $\mathrm{F}$ & $M$ & $\mathrm{~F}$ & ALL \\
\hline
\end{tabular}

PATIENTS ON TREATMENT AT THE BEGINNING OF THE PERIOD

\begin{tabular}{|l|r|r|r|r|r|r|r|r|r|}
\hline 1 Total & 75 & 34 & 3 & 4 & 22 & 5 & 4 & 0 & 147 \\
\hline
\end{tabular}

PATIENTS REGISTERED DURING THE QUARTER OF REPORT

\begin{tabular}{|l|r|r|r|r|r|r|r|r|r|}
\hline 2 New patients never treated before & 4 & 9 & 0 & 1 & 0 & 0 & 0 & 0 & 14 \\
\hline 2.1 age 0-14 years & 1 & 2 & 0 & 1 & 0 & 0 & 0 & 0 & 4 \\
\hline 2.2 age 15+ & 3 & 7 & 0 & 0 & 0 & 0 & 0 & 0 & 10 \\
\hline 2.3 With disability grade 0 & 2 & 4 & 0 & 0 & 0 & 0 & 0 & 0 & 6 \\
\hline 2.4 With disability grade 1 & 1 & 4 & 0 & 0 & 0 & 0 & 0 & 0 & 5 \\
\hline 2.5 With disability grade 2 & 0 & 0 & 0 & 1 & 0 & 0 & 0 & 0 & 1 \\
\hline 2.6 With unknown disab.grade & 0 & 1 & 0 & 0 & 0 & 0 & 0 & 0 & 1 \\
\hline 3 Relapses after MDT & 0 & 0 & 0 & 0 & 0 & 0 & 0 & 0 & 0 \\
\hline $4 \quad$ Transferred in & 1 & 1 & 0 & 0 & 0 & 0 & 0 & 0 & 2 \\
\hline 5 Re-admissions & 12 & 2 & 1 & 2 & 0 & 0 & 0 & 0 & 17 \\
\hline $6 \quad$ Total additions $(2+3+4+5)$ & 17 & 12 & 1 & 3 & 0 & 0 & 0 & 0 & 33 \\
\hline
\end{tabular}

PATIENTS REMOVED FROM THE REGISTER

\begin{tabular}{|l|r|r|r|r|r|r|r|r|r|}
\hline 7 & Treatm. completed as prescribed & 56 & 27 & 3 & 4 & 0 & 0 & 0 & 0 \\
\hline 8 Died & 0 & 1 & 0 & 0 & 1 & 0 & 0 & 0 & 90 \\
\hline 9 Transferred out & 1 & 1 & 0 & 1 & 5 & 2 & 1 & 0 & 11 \\
\hline 10 Out of control & 15 & 4 & 0 & 0 & 11 & 3 & 0 & 0 & 33 \\
\hline 11 Total deductions $(7+8+9+10)$ & 72 & 33 & 3 & 5 & 17 & 5 & 1 & 0 & 136 \\
\hline
\end{tabular}

PATIENTS ON TREATMENT AT THE END OF THE PERIOD

\begin{tabular}{|l|r|r|r|r|r|r|r|r|r|}
\hline 12 Total (1+6-11) & 20 & 13 & 1 & 2 & 5 & 0 & 3 & 0 & 44 \\
\hline 13 Patients registered for care only & 0 & 0 & 0 & 0 & 0 & 0 & 0 & 0 & 0 \\
\hline
\end{tabular}


Table 4: Treatment outcomes leprosy

\begin{tabular}{|l|r|r|r|r|}
\hline & $1995 \mathrm{MB}$ & $1996^{*} \mathrm{MB}$ & $1997 \mathrm{~PB}$ & $1998 \mathrm{~PB}$ \\
\hline Male & 24 & 25 & 8 & 5 \\
\hline Female & 16 & 13 & 2 & 1 \\
\hline Treatmerit compl. & 28 & 31 & 8 & 5 \\
\hline Out of control & 8 & 5 & 1 & 1 \\
\hline Died & 4 & 1 & 1 & \\
\hline Transferred out & & 1 & & \\
\hline Still on treatment & & & & \\
\hline \hline Total & 40 & 38 & 10 & 6 \\
\hline
\end{tabular}

* The apparent discrepancy between the numbers of MB patients reported on in the case detection report on 1996 presented earlier and the number of MB cases reported on in the cohort report on 1996, is due to records from the clinics in Behsud, Sheikh Ali and Yakaolang having been lost as a result of looting that took place in September ' 98 .

\section{Chart 1: Trends in registered incidence and prevalence of leprosy}

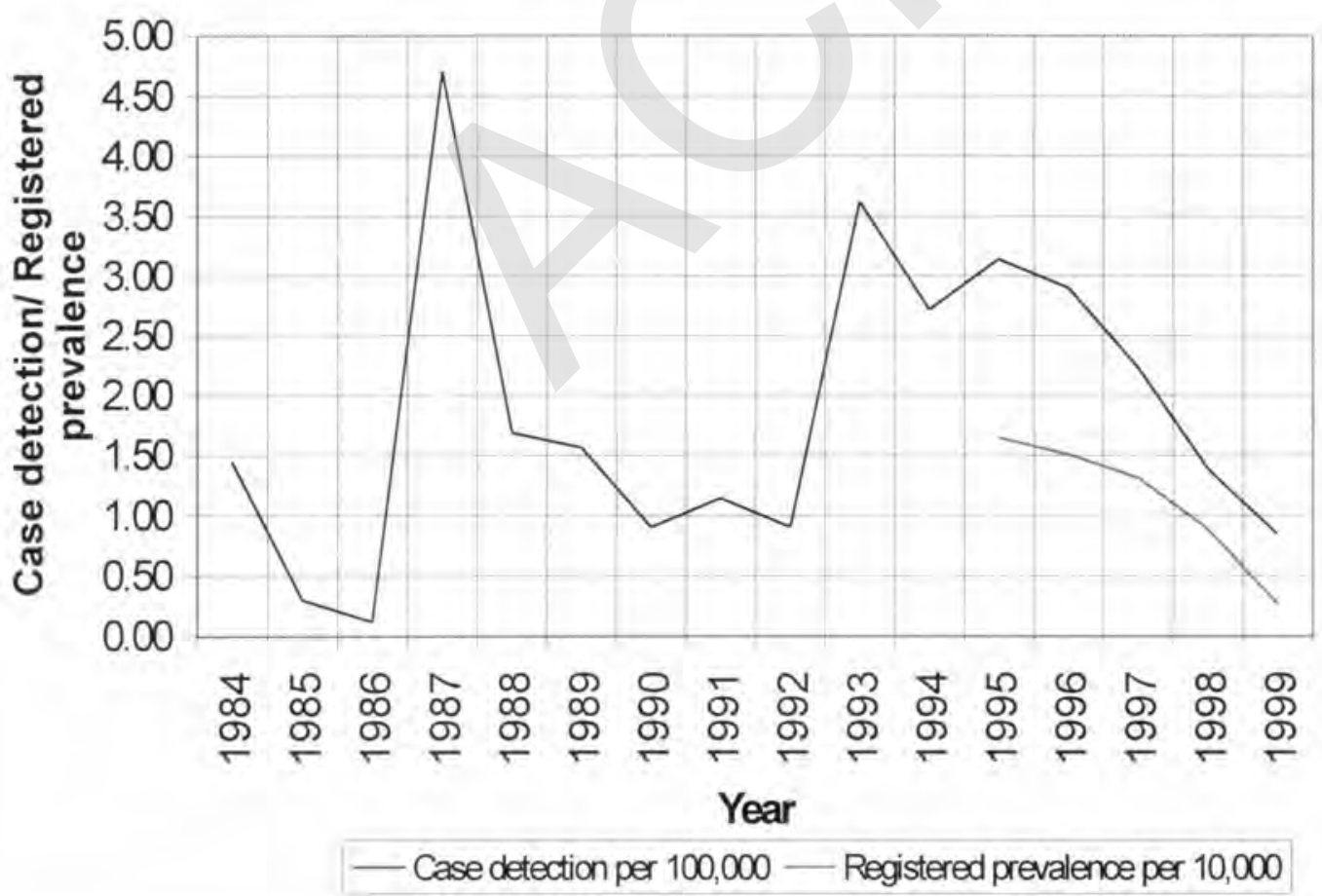




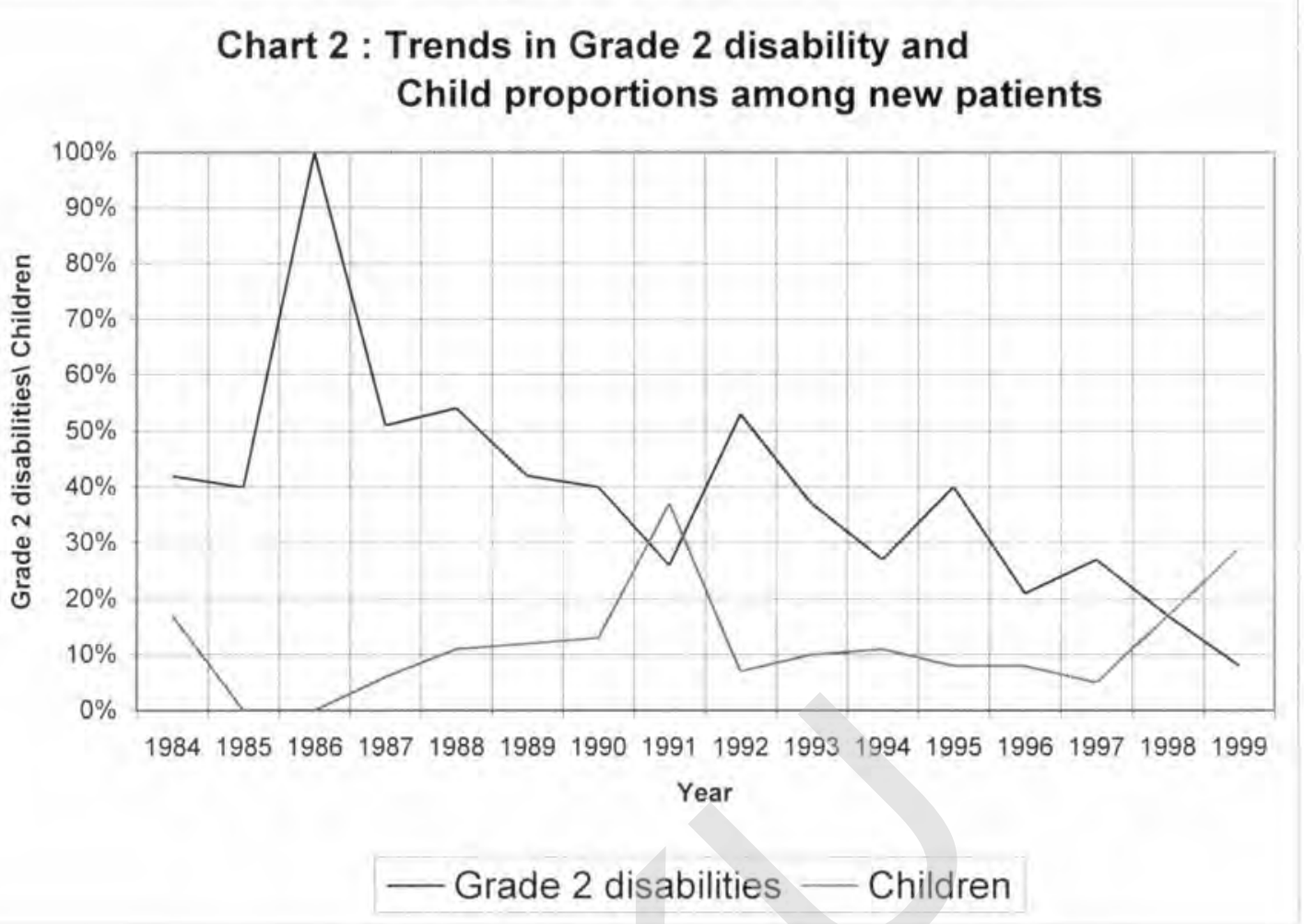




\section{Tuberculosis:}

During 1998, 117 new smear positive cases were registered, 181 were registered during the 99 until mid November. The annual incidence of new smear positive cases is estimated at 2500 for the catchment area of the LEPCO clinics. The proportion of smear positives among new cases continues to increase, from $36 \%$ in '98 it went up to $49 \%$ for the first 11 months of 1999. Further details on case detection can be found in Table 5 .

Cure rates were calculated for the 1997 and 1998 cohorts. During 1997, 95 new smear positive cases were started on treatment, 40 were cured, 40 completed treatment, 1 died, 7 became failures, 6 defaulted and 1 was transferred out. The cure rate was therefore $85 \%$ (excluding the dead). In 1998 the cure rate went down due to the disturbances in Mazar-iSharif. Altogether 117 new smear positive cases were started on treatment, of those 54 were cured, 23 completed treatment, 19 defaulted, 9 died and 12 became failures. The cure rate was therefore $71 \%$ (excluding the dead). Most of the defaulters and failures were from Mazar, most of them started treatment during the first half of 1998. For the cohort that started treatment during the second half of 1998 the cure rate was back to $87 \%$. More detailed information about treatment outcomes for the cohorts of 1997 and 1998 can be found in tables 6 and 7 respectively.

Chart 3 shows the trends of 2 months conversion and cure rates for new smear positives on short course chemotherapy. Initially in 1997 the conversion rate was lower than the cure rate as at that time follow up smears at 2 months were not routinely done in most clinics. All those considered cured are smear positive cases who have completed treatment and had at least one negative follow up smear. From the chart it can be seen how the cure rate shows a dip for those registered during the first half of 1998 . The conversion rate however continues to rise as most patients who absconded due to the disturbances in Mazar had already become smear negative at the time they were lost. For those registered during the second half of 1998, the cure rate is back at its old level.

Table 5: Case detection tuberculosis

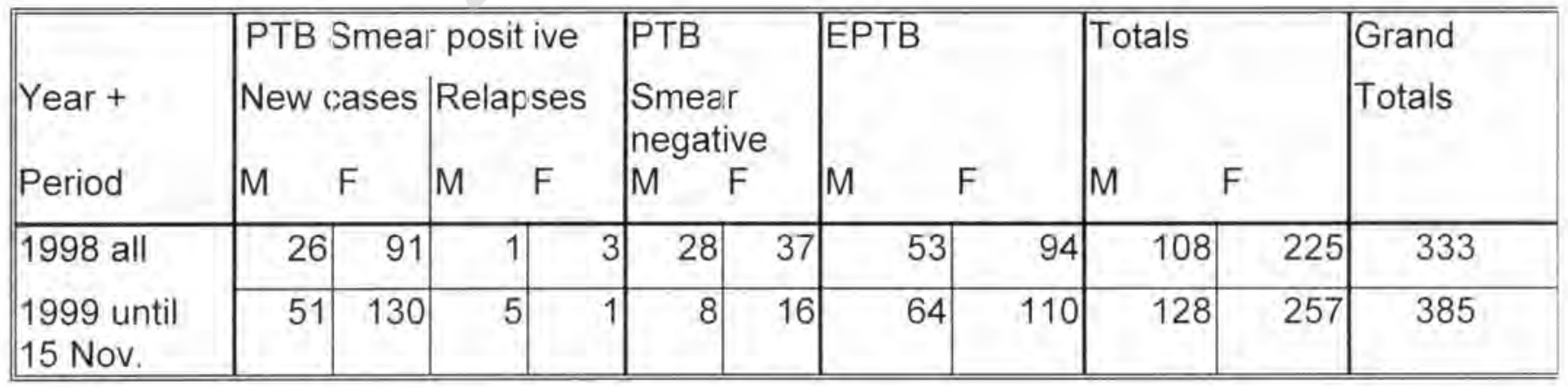




\section{Table 6: Treatment outcomes tuberculosis 1997 cohort}

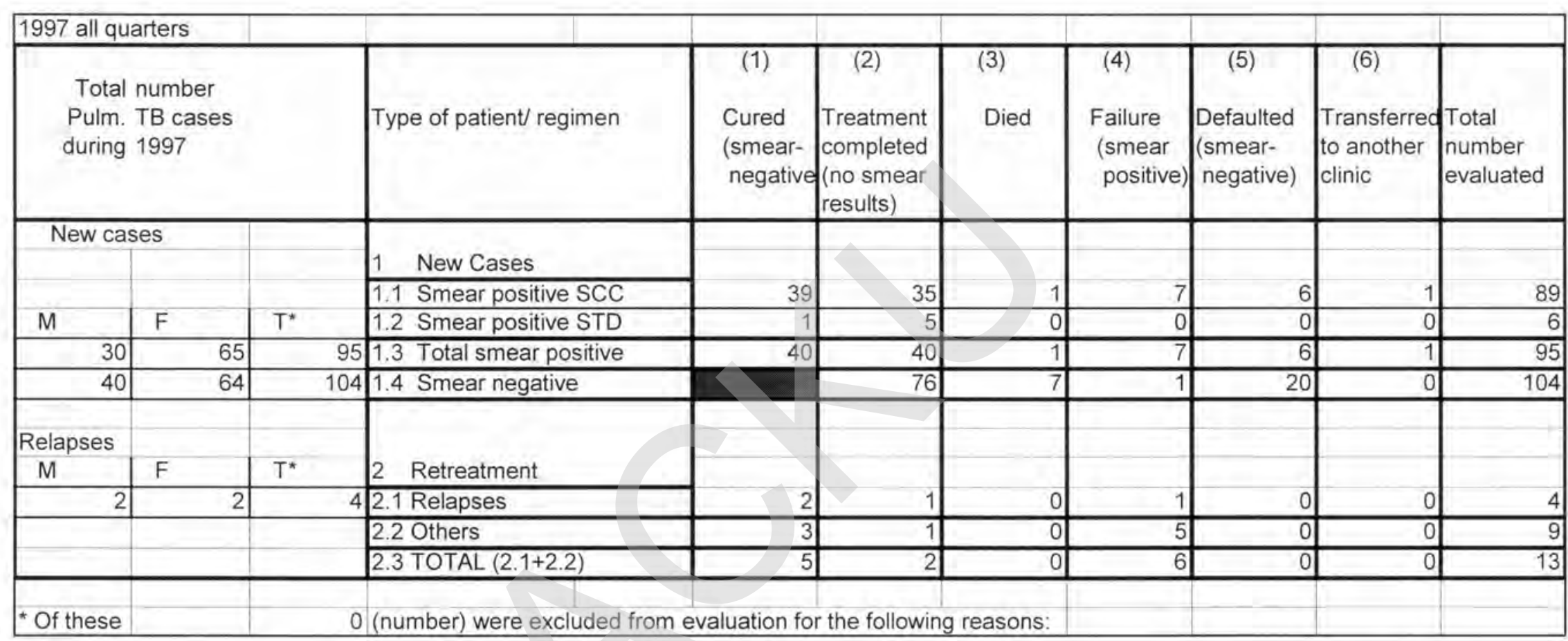


Table 7: Treatment outcomes tuberculosis 1998 cohort

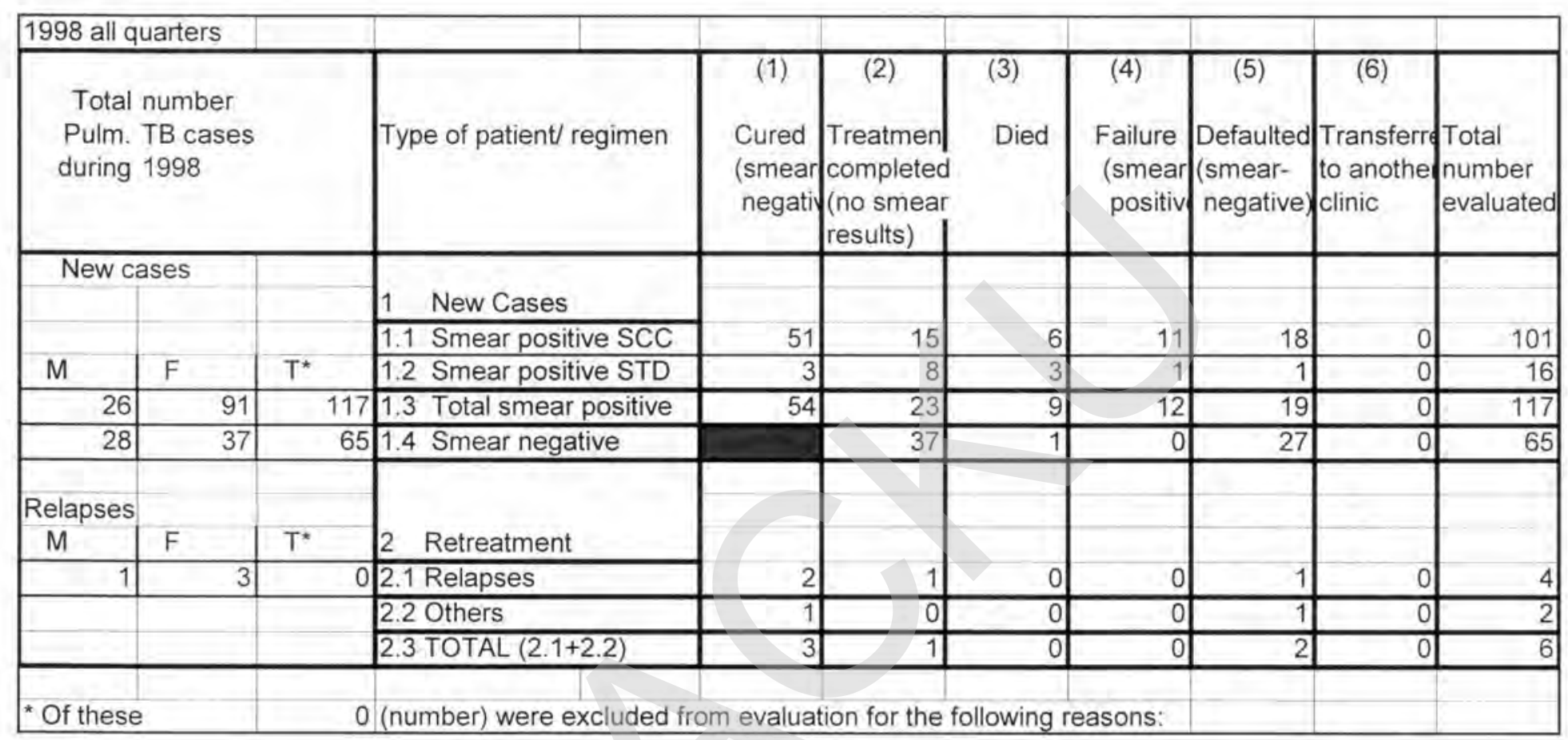




\section{Chart 3: TWO MONTHS CONVERSION AND CURE RATES \\ FOR \\ NEW SMEAR POSITIVES ON SCC}

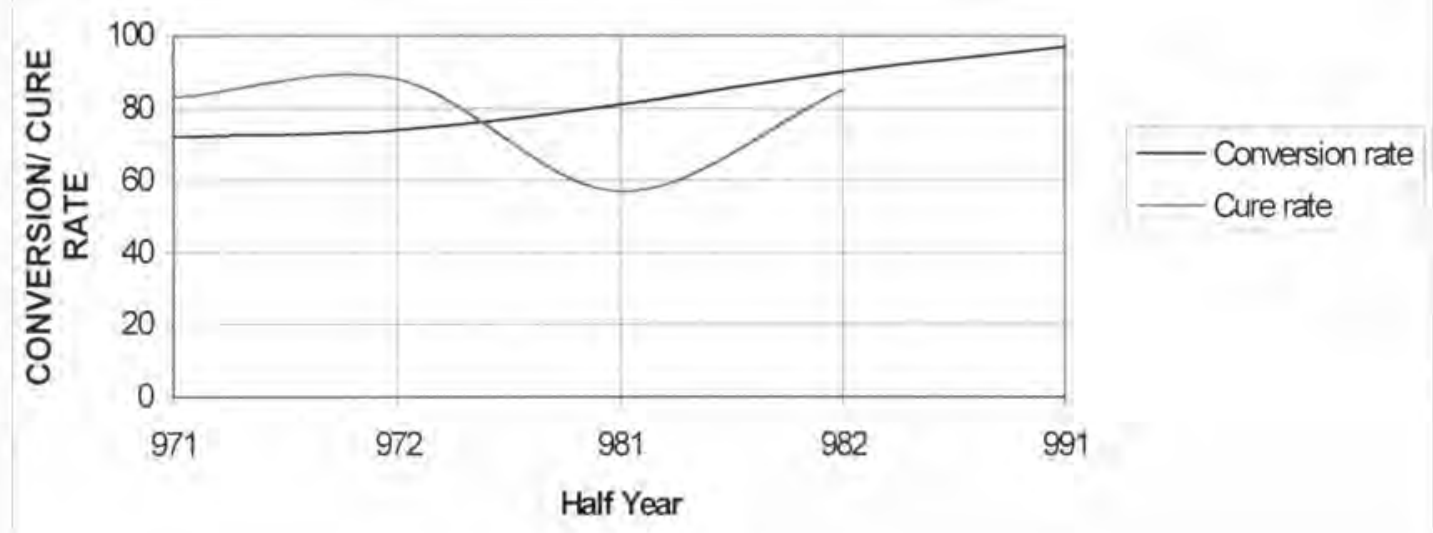

\section{General:}

During 1998 the LEPCO clinics were attended by 20,636 general patients. During the first 10 months of $1999,24,845$ general patients attended. Throughout the year only 5 clinics had been open for general patients, in those clinics attendance was almost back to the level of 1996 when 51,645 patients were seen in 9 clinics. In 1998, 20\% of general patients were children below 5 years of age, $36 \%$ were men and $44 \%$ were women. In the first ten months of $1999,27 \%$ were children, $37 \%$ were men and $36 \%$ were women. Women and young children therefore still make up more than $60 \%$ of patients attending the OPD's. Further details can be found in tables 8 and 9. 
Table 8: General patients attendance 1998

\section{LEPCO: MONTHLY HEALTH REPORT}

\begin{tabular}{|c|c|c|c|c|c|}
\hline \multirow{3}{*}{$\begin{array}{l}\text { TOTAL } 1998 \\
\text { Nature of sickness }\end{array}$} & \\
\hline & \multicolumn{2}{|c|}{$0-4$ vears } & \multicolumn{2}{|c|}{5 vrs and above } & \multirow[b]{2}{*}{ TOTAL } \\
\hline & Male & Female & male & female & \\
\hline Iniuries & 21 & 20 & 137 & 68 & 246 \\
\hline Eye infection & 27 & 15 & 100 & 79 & 221 \\
\hline Other eye problems & 16 & 19 & 49 & 40 & 124 \\
\hline Ear infection & 110 & 54 & 135 & 115 & 414 \\
\hline Other ear problems & 11 & 10 & 81 & 60 & 162 \\
\hline Upper respiratory tract infection & 110 & 83 & 383 & 458 & 1034 \\
\hline Lower respiratory tract infection & 897 & 515 & 1088 & 1230 & 3730 \\
\hline Cardio Vascular System (incl, high BP) & 9 & 3 & 239 & 390 & 641 \\
\hline Diarrhoea-simple & 367 & 277 & 133 & 100 & 877 \\
\hline Dysentery & 139 & 101 & 136 & 88 & 464 \\
\hline Chronic diarrhoea & 8 & 2 & 22 & 16 & 48 \\
\hline Worms & 138 & 97 & 507 & 338 & 1080 \\
\hline Dyspepsia/ Gastritis/ P.U.D. & 6 & 4 & 516 & 821 & 1347 \\
\hline Other gastro-intestinal problems & 20 & 32 & 185 & 385 & 622 \\
\hline Urinary tract disease & 28 & 23 & 455 & 706 & 1212 \\
\hline Nervous system disease & 3 & 2 & 115 & 96 & 216 \\
\hline Musculo-skeletal disease & 9 & 6 & 893 & 1118 & 2026 \\
\hline Dental/ Mouth problems & 8 & 19 & 245 & 249 & 521 \\
\hline Skin infection & 124 & 45 & 421 & 321 & 911 \\
\hline Non infectious skin problems + allergy & 58 & 37 & 336 & 279 & 710 \\
\hline Malaria & 2 & 0 & 5 & 3 & 10 \\
\hline Fever of unknown origin & 60 & 37 & 63 & 55 & 215 \\
\hline Malnutrition & 65 & 50 & 186 & 205 & 506 \\
\hline Anaemia & 6 & 24 & 68 & 691 & 789 \\
\hline Obstetrics - Antenatal & 0 & 0 & 0 & 63 & 63 \\
\hline Obstetrics - Post natal & 0 & 0 & 0 & 49 & 49 \\
\hline Gynaecological/ PID & 0 & 0 & 0 & 113 & 113 \\
\hline S.T.D. & 0 & 0 & 0 & 1 & 1 \\
\hline Goiter & 0 & 5 & 44 & 113 & 162 \\
\hline Jaundice/ Liver disease & 2 & 5 & 18 & 20 & 45 \\
\hline Measles & 4 & 3 & 1 & 0 & 8 \\
\hline Diphtheria & 0 & 0 & 0 & 0 & 0 \\
\hline Neonatal tetanus & 0 & 0 & 0 & 0 & 0 \\
\hline Tetanus - Other cases & 0 & 0 & 0 & 0 & 0 \\
\hline Whooping cough & 73 & 65 & 6 & 14 & 158 \\
\hline Poliomyelitis & 0 & 0 & 2 & 1 & 3 \\
\hline Meningitis & 3 & 0 & 1 & 1 & 5 \\
\hline Psychiatric & 1 & 3 & 31 & 23 & 58 \\
\hline Others & 177 & 90 & 837 & 741 & 1845 \\
\hline TOTAL NUMBER Of PATIENTS & 2502 & 1646 & 7438 & 9050 & 20636 \\
\hline
\end{tabular}


Table 9: General patients attendance 1999 January - October

\section{LEPCO: MONTHLY HEALTH REPORT}

\begin{tabular}{|c|c|c|c|c|c|}
\hline \multirow{3}{*}{$\begin{array}{l}\text { 1999 Januarv - October } \\
\text { Nature of sickness }\end{array}$} & \multirow{2}{*}{\multicolumn{2}{|c|}{$\sqrt{0-4 \text { vears }}$}} & & & \multirow[b]{3}{*}{ TOTAL } \\
\hline & & & \multicolumn{2}{|c|}{5 vrs and above } & \\
\hline & Imale & Female & Imale & female & \\
\hline Injuries & 69 & 49 & 203 & 79 & 400 \\
\hline Eye infection & 144 & 90 & 275 & 166 & 675 \\
\hline Other eye problems & 2 & 15 & 111 & 62 & 190 \\
\hline Ear infection & 160 & 142 & 189 & 116 & 607 \\
\hline Other ear problems & 33 & 19 & 92 & 42 & 186 \\
\hline Upper respiratory tract infection & 262 & 270 & 684 & 680 & 1896 \\
\hline Lower respiratory tract infection & 471 & 312 & 706 & 783 & 2272 \\
\hline Cardio Vascular System (incl. high BP) & 9 & 4 & 350 & 394 & 757 \\
\hline Diarrhoea - simple & 293 & 275 & 151 & 103 & 822 \\
\hline Dysentery & 228 & 187 & 231 & 125 & 771 \\
\hline Chronic diarrhoea & 63 & 65 & 46 & 18 & 192 \\
\hline Worms & 391 & 408 & 592 & 318 & 1709 \\
\hline Dyspepsia/ Gastritis/ P.U.D. & 103 & 85 & 743 & 851 & 1782 \\
\hline Other gastro-intestinal problems & 15 & 34 & 368 & 509 & 926 \\
\hline Urinary tract disease & 119 & 108 & 659 & 840 & 1726 \\
\hline Nervous system disease & 0 & 3 & 79 & 71 & 153 \\
\hline Musculo-skeletal disease & 29 & 33 & 880 & 959 & 1901 \\
\hline Dental/ Mouth problems & 111 & 124 & 382 & 300 & 917 \\
\hline Skin infection & 136 & 158 & 364 & 173 & 831 \\
\hline Non infectious skin problems + allergy & 165 & 176 & 561 & 377 & 1279 \\
\hline Malaria & 5 & 1 & 22 & 2 & 30 \\
\hline Fever of unknown origin & 158 & 162 & 284 & 195 & 799 \\
\hline Malnutrition & 165 & 225 & 136 & 94 & 620 \\
\hline Anaemia & 6 & 5 & 81 & 512 & 604 \\
\hline Obstetrics - Antenatal & 0 & 0 & 0 & 68 & 68 \\
\hline Obstetrics - Post natal & 0 & 0 & 0 & 67 & 67 \\
\hline Gynaecological/PID & 0 & 5 & 0 & 233 & 238 \\
\hline S.T.D. & 0 & 0 & 6 & 7 & 13 \\
\hline Goiter & 19 & 17 & 93 & 124 & 253 \\
\hline Jaundice/ Liver disease & 9 & 1 & 43 & 24 & 77 \\
\hline Measles & 29 & 40 & 20 & 7 & 96 \\
\hline Diphtheria & 0 & 0 & 1 & 1 & 2 \\
\hline Neonatal tetanus & 0 & 0 & 0 & 0 & 0 \\
\hline Tetanus - Other cases & 7 & 10 & 9 & 8 & 34 \\
\hline Whooping cough & 128 & 136 & 17 & 5 & 286 \\
\hline Poliomyelitis & 0 & 0 & 1 & 0 & 1 \\
\hline Meningitis & 1 & 1 & 24 & 28 & 54 \\
\hline Psychiatric & 2 & 0 & 14 & 43 & 59 \\
\hline Others & 162 & 78 & 709 & 612 & 1561 \\
\hline TOTAL NUMBER Of PATIENTS & 3494 & 3238 & 9126 & 8996 & 24854 \\
\hline
\end{tabular}




\section{Financial aspects:}

Altogether inputs equivalent to an amount of US\$275,737 were received from Misereor (US\$87,417), Caritas (US\$92,318), GLRA (US\$56,324), the German Ministry of Foreign Affairs (US\$29,649), the German embassy in Islamabad (US\$7,223) and patient contributions (US\$2,805). The balance at the beginning of the year was equivalent to US $\$ 93,632$. In total an amount equivalent to US $\$ 333,994$ was spent, the balance at the end of the year was equivalent to US\$28,035. A discrepancy of US\$7,340 is due to losses sustained in robberies and looting that took place in the second half of 1998. This amount has been booked in 1999, as it wasn't until the spring of 1999 that the exact amounts lost could be established. Only then we were able to reach our project areas again. In the table on page 26 it is indicated how the expenditure was divided over the various ILEP budget items. Apparent minor inaccuracies are due to rounding. For detailed information, I would like to refer to the 1999 financial report of LEPCO, 
Table 10 : Expenditure LEPCO 1999

\begin{tabular}{|c|c|c|}
\hline $\begin{array}{l}\text { Ilep } \\
\text { nr. }\end{array}$ & Description & $\begin{array}{l}\text { Amount spent } \\
\text { converted to USS }\end{array}$ \\
\hline 1 & Investments (Capital Expenditure) & \\
\hline 1.1 & Buildings & 36,731 \\
\hline 1.2 & Medical equipment & 2,666 \\
\hline 1.3 & General equipment & 15,740 \\
\hline 1,4 & Vehicles & 15,359 \\
\hline 1.5 & Equipment for rehabilitation and vocational training & \\
\hline 1.6 & Miscellaneous & \\
\hline 1.7 & Total Investments & 70,495 \\
\hline 2 & Salaries, Staff, Training Expenses & \\
\hline 2.1 & Medical doctors & 825 \\
\hline 2.2 & Other medical, paramedical and technical staff & 50,424 \\
\hline 2.3 & Administrative/maintenance staff & 60,055 \\
\hline 2.4 & Staff benefits & 3,880 \\
\hline 2.5 & Training & 2,488 \\
\hline 2.6 & Miscellaneous & \\
\hline 2.7 & Total Salaries, Staff and Training Expenses & 117,673 \\
\hline 3 & Maintenance (Running Costs) & \\
\hline 3.1 & Repairs and utilities & 22,548 \\
\hline 3.2 .1 & Anti-leprosy drugs & 0 \\
\hline 3.2 .2 & Anti -TB drugs & 20,836 \\
\hline 3.3 & Other drugs and medical supplies & 42,955 \\
\hline 3.4 & Vehicle maintenance, travel and transportation & 37,759 \\
\hline 3.5 & General supplies/ welfare and social activities & 11,589 \\
\hline 3.6 & Miscellaneous & \\
\hline 3.7 & Total Maintenance & 135,687 \\
\hline & & \\
\hline 4 & Administration & \\
\hline 4.1 & Office expenses & 9,688 \\
\hline 4.2 & 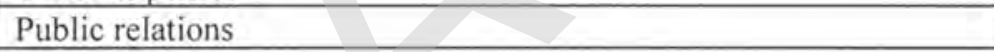 & 331 \\
\hline 4.3 & Special budget & 0 \\
\hline 4.4 & Health education activities & 0 \\
\hline 4.5 & Teaching material & 120 \\
\hline 4.6 & Miscellaneous & \\
\hline \multirow[t]{3}{*}{4.7} & Total Administration & 10,139 \\
\hline & & \\
\hline & GRAND TOTAL & 333,994 \\
\hline
\end{tabular}




\section{Conclusion:}

1999 has been a successful year for LEPCO. Most of the planned activities have been carried out as planned. The TB control program was further strengthened and some major steps were taken towards integration of the program into existing general health services. The program seems to have survived the troubles of 1998 fairly well. It has become clear that the LEPCO program is a fairly robust program, well equipped to face the conditions of war in Afghanistan. Nevertheless it is hoped that the current situation with relatively little fighting will continue or improve even further.

Fewer and fewer new cases of leprosy are found, a trend that is confirmed by other organizations active in this field in Afghanistan. In the tuberculosis program, case detection of new smear positive patients is on the rise and expected to rise even further this year. With the clinics in Chak, Panjao, Mazar and Behsud open all year and the clinics in Bamyan and Yakaolang to be re-opened in summer, the number of smear positive cases detected might once again double during the year 2000. The high sputum conversion rate seen for the first 8 months of 1999 and the restoration of the high cure rate for the cohort of the second half of 1998 are indicators that the program is running well.

In the coming years we hope to be able to further increase the scope of the TB control program, while maintaining a high cure rate. Controlling tuberculosis in Afghanistan under the present circumstances may not be a realistic target, but a lot of human suffering can be alleviated. In leprosy the epidemic appears to be on its last legs, but unless control efforts are maintained for at least another decade, the situation may again be reversed.

Finally I wish to thank all our donors for the support given to LEPCO. We appreciate very much your continued support after two difficult years in which, due to an upsurge in the fighting in Afghanistan, there were many losses and less output than might have been expected under normal circumstances. 1999 has been a better year, we hope favorable conditions will persist in the year 2000.

Peshawar 6 January 2000 ,

Dr. Epco Hasker,

Medical Co-ordinator 


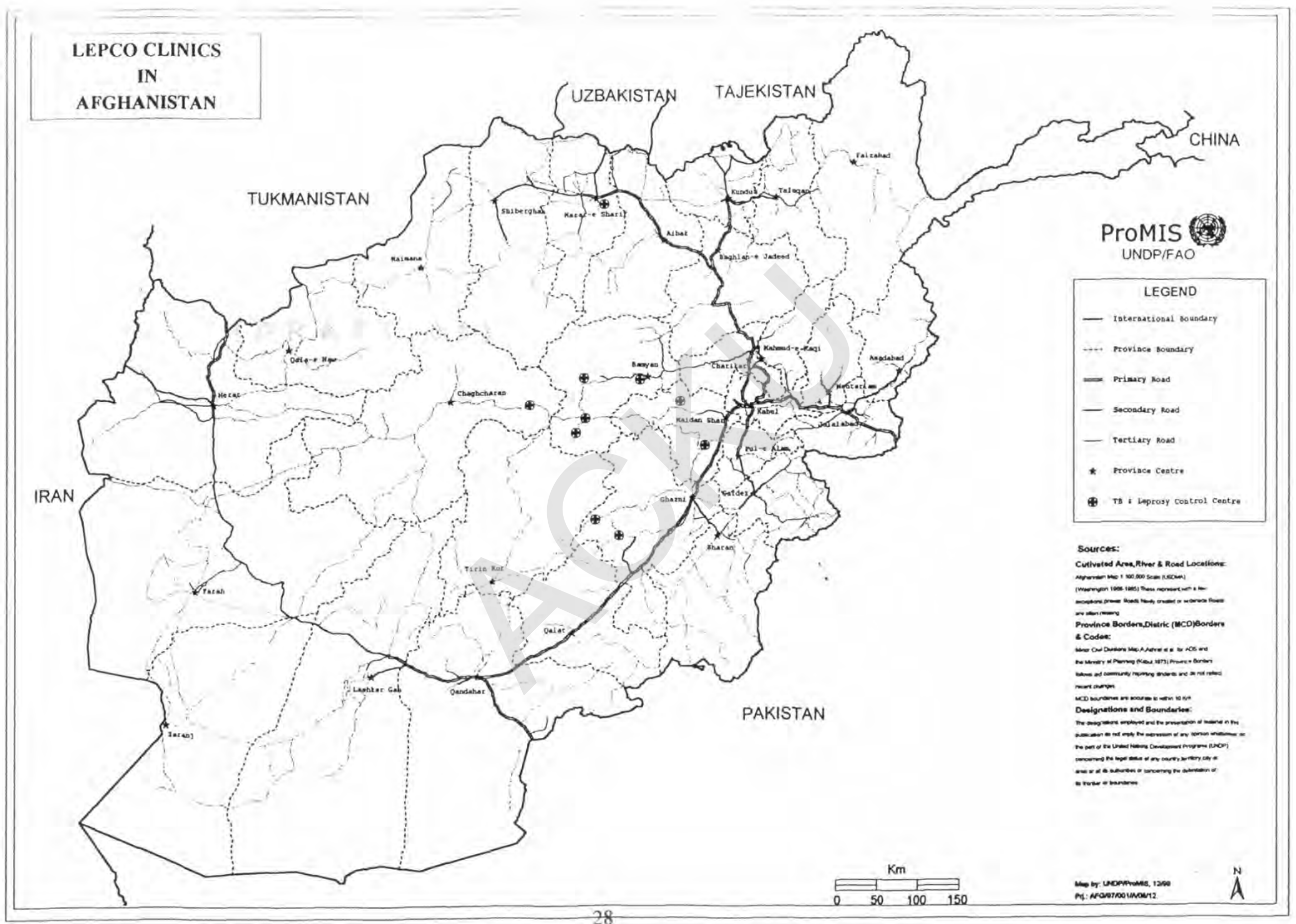




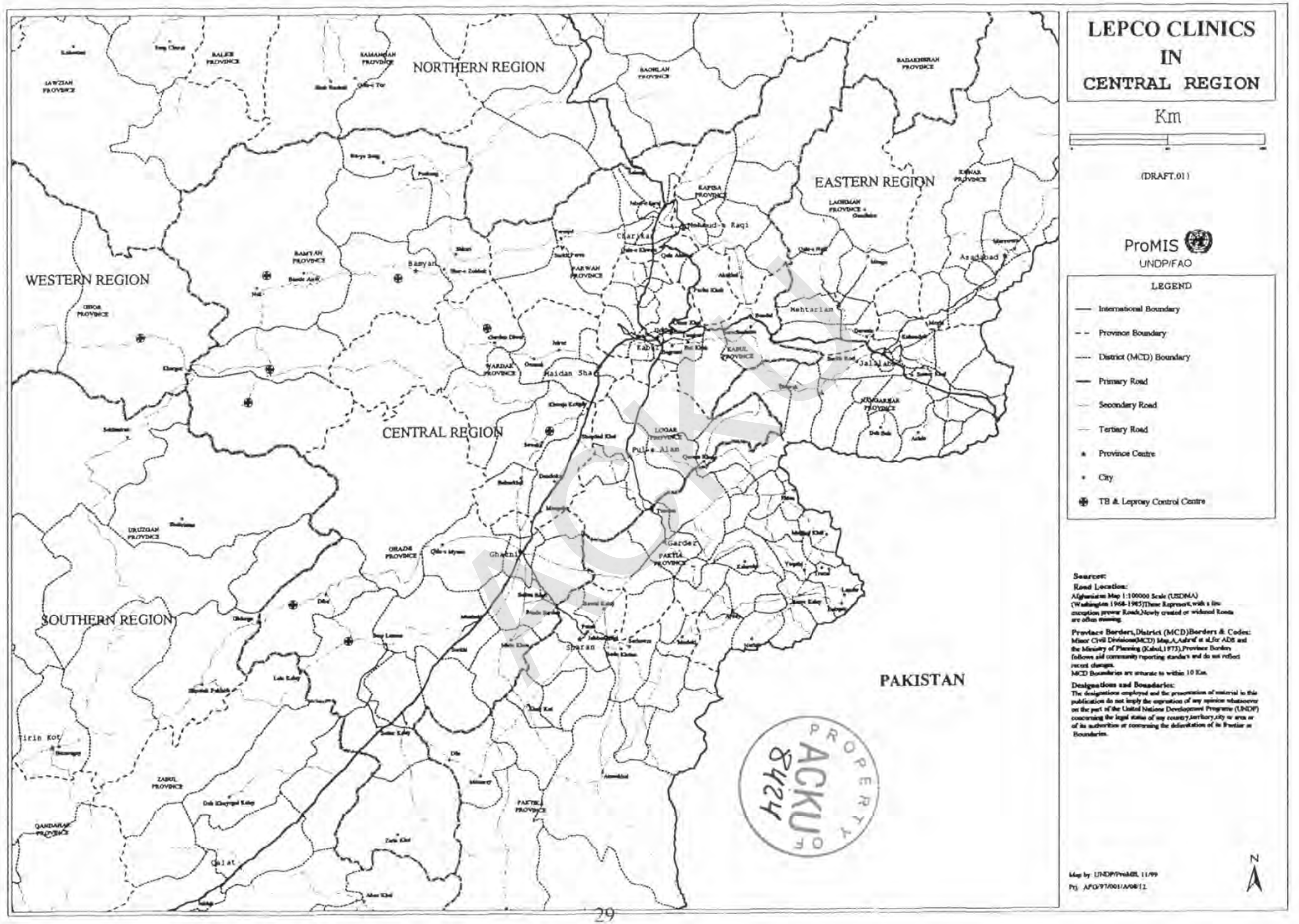

